PArker, C. D. \& Prisk, J. (1953). J. gen. Microbiol. 8, 344-364.

\title{
The Oxidation of Inorganic Compounds of Sulphur by various Sulphur Bacteria
}

\author{
By C. D. PARKER ANd JOYCE PRISK \\ Melbourne and Metropolitan Board of Works, Research Laboratory, \\ 70-80 Wells Street, South Melbourne, S.C. 4, Australia
}

SUMMARY: Cultures of Thiobacillus thiooxidans, Th. thioparus, Th. novellus, Thiobacillus $B$ (Waksman, 1922a), strains ' $T$ ' and ' $K$ ' (Trautwein, 1921) and Th. concretivorus, Thiobacillus $X$ and the ' $M$ ' strains, organisms isolated from concrete (Parker, 1945, 1947), were examined to elucidate the mode of oxidation and to establish the identity of the organisms recently isolated from corroded concrete.

'Thiosulphate was oxidized by all these bacteria. Th. thiooxidans, Th. concretivorus and Thiobacillus $\boldsymbol{X}$ first converted it to tetrathionate and sulphate and then oxidized the tetrathionate to sulphate and free sulphuric acid. Thiobacillus $\boldsymbol{X}$ differed from the other two in that, owing to a lesser acid tolerance, some tetrathionate was found in the final products of oxidation. Th. thioparus converted thiosulphate to sulphate and sulphur, followed by partial oxidation of the sulphur to sulphuric acid. Th. novellus produced sulphate and sulphuric acid. Thiobacillus $B$, the ' $T$ ' and ' $K$ ' strains and the ' $M$ ' strains formed sulphate and tetrathionate with temporary increase in $\mathrm{pH}$ value; only Thiobacillus $\boldsymbol{X}$ oxidized tetrathionate, yielding sulphate and sulphuric acid.

Elementary sulphur was oxidized by $T h$. thiooxidans, Th. concretivorus, Thiobacillus $X$ and $T h$. thioparus; the rates of oxidation decreased in that order, and the only product was sulphuric acid.

Hydrogen sulphide was oxidized only at low concentrations and only by $T h$. concretivorus and Thiobacillus $\boldsymbol{X}$; sulphuric acid was the end-product, and elementary sulphur may have been an intermediate.

Thiobacillus $\boldsymbol{X}$ differed from $T h$. thiooxidans in $\mathrm{pH}$ range for growth and from Th. thioparus in its method of oxidation of thiosulphate, tetrathionate and $\mathrm{H}_{2} \mathrm{~S}$. It appeared to fit earlier descriptions of Th. thioparus by Nathansohn (1902) and Beijerinck (1904) more closely than the strain described as Th. thioparus by Starkey (1934 a). The ' $M$ ' strains were similar to Thiobacillus $B$ and the ' $T$ ' and ' $K$ ' strains of Trautwein.

Species of micro-organisms capable of oxidizing inorganic sulphur compounds fall into three main groups: those which oxidize hydrogen sulphide autotrophically and deposit sulphur intra- or extracellularly, including members of the Beggiatoaceae, Thiorhodaceae and Chlorobacteriaceae families of the classification of Bergey's Manual (1948); members of the genus Thiobacillus which oxidize a wide variety of sulphur compounds; various heterotrophic organisms such as Pseudomonas spp. which appear to have a much more limited ability for oxidation.

Difficulty in isolating pure cultures of members of the first group has retarded the elucidation of their metabolic activities. However, pure culture studies of the Thiorhodaciae and Chlorobacteriaceae by van Niel (1931) have thrown considerable light on the mechanism of photosynthesis by these organisms. Detailed studies of the oxidative ability of organisms of the second and third 
groups were made by Starkey $(1925,1934 b, 1935 a)$. More recently, the work of Umbreit and colleagues (Vogler, 1942; Vogler \& Umbreit, 1942; LePage \& Umbreit, 1943) with Thiobacillus thiooxidans, has revealed something of the nature of the chemosynthetic process.

However, the ability of several species of the second and third groups to oxidize some forms of sulphur remains uncertain, and the exact course of the oxidation is still open to doubt. To help resolve these points and to establish the identity of species of sulphur bacteria recently isolated from corroded concrete (Parker, 1945, 1947) an examination of several species of bacteria able to oxidize inorganic sulphur compounds has been made and some of Starkey's work has been repeated in greater detail. Three types of organism isolated from concrete were examined: the autotrophic $T h$. concretivorus (Parker, 1945); the Th. thioparus-like autotrophic type (Parker, 1947) here referred to as Thiobacillus $X$; a miscellaneous collection of heterotrophic types (Parker, 1947) here referred to as the ' $M$ ' strains; strains of Th. thiooxidans, Th. thioparus, Th. novellus, Thiobacillus $B$ (Waksman); strains ' $\mathrm{T}$ ' and ' $\mathrm{K}$ ' of Trautwein. These latter were kindly supplied by Dr R. L. Starkey and, except for $T h$. thioparus, were subcultures of those originally isolated. The strain of Th. thioparus was a subculture of an organism isolated by Starkey $(1934 a)$ and considered by that author to be identical with the original strain isolated by Nathansohn (1902) and named by Beijerinck (1904).

\section{METHODS}

Media. The constituents of the basal media used are shown in Table 1. To study the oxidation of the various inorganic sulphur compounds, appropriate alterations were made in the sulphur compound added.

Table 1. Composition of media used in study of oxidation by various sulphur bacteria

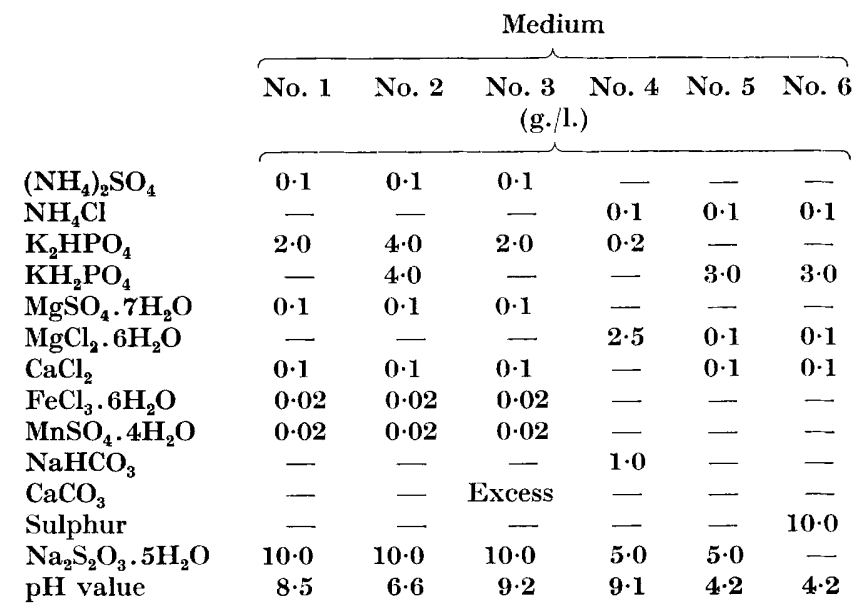

Media 1 and 2 are those used by Starkey $(1934 a)$; medium 3 is similar to his no. 3. Media 4, 5 and 6 are similar to those used by Beijerinck (1904). 
The rate of oxidation could be varied by altering the ratio of surface area exposed to air to volume of culture medium, so appropriate volumes of medium were placed in Erlenmeyer flasks depending on the speed of reaction desired. In general, $100 \mathrm{ml}$. medium was used in a $300 \mathrm{ml}$. Erlenmeyer flask. Separate flasks were taken for analysis at intervals. In some experiments, however, 1.5 l. medium was used in a 2 l. flask and samples were taken at intervals from it.

Media containing thiosulphate were steamed in bulk on three successive days and then distributed aseptically in $100 \mathrm{ml}$. lots into sterile $300 \mathrm{ml}$. Erlenmeyer flasks. Medium 6 was autoclaved in separate flasks and the sulphur was steamed in test tubes and then added to the medium.

Media containing tetrathionate were incubated in $50 \mathrm{ml}$. lots in $100 \mathrm{ml}$. Erlenmeyer flasks. Potassium tetrathionate was prepared in this laboratory as follows: Wackenroder's solution was prepared by passing $\mathrm{H}_{2} \mathrm{~S}$ through a saturated solution of sulphurous acid held just above $0^{\circ}$ (Debus, 1888). When the reaction was completed sulphur was filtered off and the solution concentrated to sp.gr. 1.32 by evaporation on a water-bath. Potassium salts of the mixed thionic acids were then prepared by the addition of a saturated solution of potassium acetate to the concentrated Wackenroder's solution. The potassium salts were allowed to crystallize for $24 \mathrm{hr}$. and crystalline pentathionate and tetrathionate filtered off. The mixed crystalline mass was recrystallized from water slightly acidified with sulphuric acid and the potassium tetrathionate separated by hand picking typical crystals. It was possible in this way to separate material which appeared to be pure potassium tetrathionate; this was again recrystallized from $90 \%(\mathrm{v} / \mathrm{w})$ ethanol. The final product was shown to be free from thionates other than tetrathionate by the analytical methods described below.

Inoculum. Suspensions of the various strains were obtained by washing the growth from an agar slope with 1-2 ml. sterile distilled water containing thiosulphate; $\mathbf{0 . 2 5} \mathrm{ml}$. of this suspension was used to inoculate each flask. With cultures which grew well on agar medium the number of organisms in the culture medium immediately after inoculation was about $10^{6} / \mathrm{ml}$., while cultures which grew poorly on agar medium, such as $T h$. novellus, gave an initial viable count of about $10^{3} / \mathrm{ml}$.

Incubation. Cultures were incubated at $28^{\circ}$, except for those grown in an atmosphere of hydrogen sulphide. Loss of water during prolonged incubation was minimized by using small incubators each containing a shallow vessel of water. When hydrogen sulphide oxidation was examined, the inoculated flasks were incubated at room temperature (about $18^{\circ}$ ) in a glass box, through which was passed air containing approximately 200 p.p.m. $\mathrm{H}_{2} \mathrm{~S}$.

Analyses. Usually a whole flask was taken for analysis; when significant evaporation had occurred, the contents were first transferred to a standard flask and diluted with sterile distilled water to the original volume. The bacterial count was determined by serial tenfold dilution of $1 \mathrm{ml}$. medium in sterile distilled water and inoculation of the dilutions into appropriate culture medium. This procedure was only accurate to a power of 10 , but was sufficiently 
accurate to indicate the major changes in population during incubation. The $\mathrm{pH}$ values were determined electrometrically.

Cultures were filtered through asbestos in Gooch crucibles into dry flasks, to remove elementary sulphur. The sulphur adhering to the incubated flask was later removed and washed into the same crucible. Samples from the filtered culture were quickly measured and the analyses begun at once, as in some cases decomposition of the solution, shown by clouding, took place very soon after filtration.

Thiosulphate, polythionate, tri-, tetra- and pentathionate, and elementary sulphur were determined by the methods of Starkey (1935a). The term 'elementary sulphur' is used to describe any form of insoluble sulphur precipitated during growth. Sulphates were determined gravimetrically as $\mathrm{BaSO}_{4}$. Sulphide was determined by the methylene-blue method of Pomeroy (1936), except in media where it was inapplicable. In these cases the antimony sulphide method (Standard Methods of Water Analysis, American Public Health Association, 8th ed.) was used. Sulphide was determined as 'sulphide after acidification' without reference as to whether the sulphide was present as dissolved hydrogen sulphide, hydrosulphide, or polysulphide. The analytical results for the various forms of sulphur are recorded in the Tables as mg. S/l. culture medium.

\section{RESULTS}

Thiobacillus concretivorus

Thiosulphate oxidation. The method of oxidation of thiosulphate by this strain has been described (Parker, 1945). In the present investigation a more detailed examination of the course of reaction was made. Flasks of medium 5 were inoculated with a young culture and analysed at frequent intervals. Two different strains were examined, but, as they behaved similarly, the results with one strain only are shown (Table 2). The chemical changes fell into two

Table 2. Oxidation of thiosulphate by Thiobacillus concretivorus

Cultures in medium 5 were analysed at intervals after inoculation

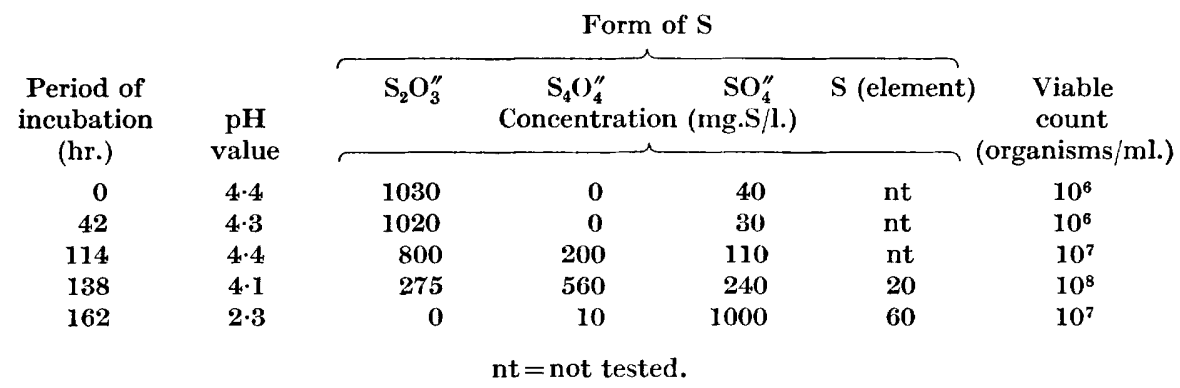

stages: (1) during oxidation of the thiosulphate and before its complete disappearance, substantial quantities of polythionate were detected; (2) quantitative examination indicated that the polythionate was almost entirely tetrathionate. Tetrathionate persisted until all the thiosulphate had been 
oxidized. Owing to the rapidity of oxidation, polythionates could only be detected over a period of 2 or 3 days. This transitory occurrence of polythionate was no doubt responsible for the failure to detect it in the previous work. During the conversion of thiosulphate to tetrathionate, there was very little change in $\mathrm{pH}$ value of the medium. There was a definite increase in sulphate and the bacterial count also increased. Very small amounts of elementary sulphur were formed.

After the complete disappearance of thiosulphate, the tetrathionate disappeared, this change being completed within $\mathbf{2 4} \mathrm{hr}$. It was accompanied by a further increase in sulphate concentration, a very marked decrease in $\mathrm{pH}$ value and the formation of a further small amount of elementary sulphur. The bacterial count remained high during this stage.

No further chemical change of any magnitude occurred after the complete oxidation of tetrathionate to sulphate, but the culture remained viable for at least a further 6 days. This was probably due to the presence of the small amounts of elementary sulphur which served as a further source of energy after thiosulphate and tetrathionate had disappeared.

Starkey (1925) found that the course of oxidation of thiosulphate by $T h$. thiooxidans was influenced by the thiosulphate concentration. The influence of concentration of thiosulphate on the course of oxidation was therefore examined with Th. concretivorus. Batches of medium 5, with thiosulphate

Table 3. Effect of initial thiosulphate concentration on oxidation of thiosulphate by Thiobacillus concretivorus

Cultures in medium 5 with various initial concentrations of $\mathrm{Na}_{2} \mathrm{~S}_{2} \mathrm{O}_{3}$ were analysed at intervals after inoculation.

$\begin{array}{cr}\begin{array}{c}\text { Initial } \\ \text { thiosulphate } \\ \text { concentration } \\ \left(\% \mathrm{Na}_{2} \mathrm{~S}_{2} \mathrm{O}_{3}\right)\end{array} & \begin{array}{c}\text { Period of } \\ \text { incubation } \\ (\mathrm{hr} .)\end{array} \\ 1 & 0 \\ & 42 \\ & 114 \\ & 162 \\ & 210 \\ & 306 \\ & 0 \\ 2 & 144 \\ & 240 \\ & 264 \\ & 336 \\ & 600 \\ & 0 \\ 4 & 120 \\ & 288 \\ & 480 \\ & 624 \\ & 840\end{array}$

\begin{tabular}{|c|c|c|c|c|c|}
\hline \multirow{3}{*}{$\begin{array}{c}\mathrm{pH} \\
\text { value }\end{array}$} & \multicolumn{4}{|c|}{ Form of $\mathrm{S}$} & \multirow{3}{*}{$\begin{array}{c}\text { Viable } \\
\text { count } \\
\text { (organisms } \\
\text { ml.) }\end{array}$} \\
\hline & $\mathrm{S}_{2} \mathrm{O}_{3}^{\prime \prime}$ & $\mathrm{S}_{4} \mathrm{O}_{6}^{\prime \prime}$ & $\mathrm{SO}_{4}^{\prime \prime}$ & $\begin{array}{c}S \\
\text { element }\end{array}$ & \\
\hline & \multicolumn{4}{|c|}{ Concentration (mg. S/litre) } & \\
\hline $4 \cdot 6$ & 2,580 & 0 & 30 & 0 & $10^{6}$ \\
\hline $4 \cdot 2$ & 2,510 & 40 & nd & 0 & $10^{6}$ \\
\hline $4 \cdot 7$ & 1,545 & 370 & nd & 10 & $10^{2}$ \\
\hline $2 \cdot 6$ & 0 & 870 & nd & 100 & $10^{7}$ \\
\hline nd & $\mathbf{0}$ & 20 & nd & 240 & $10^{7}$ \\
\hline nd & 0 & 0 & 2,590 & 10 & $10^{3}$ \\
\hline $4 \cdot 6$ & 5,250 & 0 & 60 & 0 & $10^{6}$ \\
\hline $4 \cdot 6$ & 4,370 & 400 & nd & 60 & $10^{6}$ \\
\hline $4 \cdot 6$ & 3,250 & 940 & nd & nd & nd \\
\hline $\mathbf{3} \cdot \mathbf{3}$ & 180 & 680 & nd & 120 & $10^{7}$ \\
\hline $\mathbf{1} \cdot \mathbf{3}$ & 0 & 10 & nd & 380 & 10 \\
\hline $1 \cdot 6$ & 0 & 0 & 5,200 & 130 & 10 \\
\hline 4.7 & 10,360 & 0 & 60 & 0 & $10^{6}$ \\
\hline 4.9 & 9,580 & 0 & nd & 60 & $10^{5}$ \\
\hline $4 \cdot 9$ & 8,490 & 0 & nd & 550 & $10^{2}$ \\
\hline $4 \cdot 6$ & 3,320 & 2,770 & nd & nd & $10^{6}$ \\
\hline $3 \cdot 7$ & 2,660 & 1,190 & nd & 1,010 & $10^{4}$ \\
\hline $1 \cdot 8$ & 0 & 0 & 8,770 & 1,290 & 0 \\
\hline
\end{tabular}


concentrations of $1.0 \%(\mathrm{w} / \mathrm{v}), 2.0 \%(\mathrm{w} / \mathrm{v})$ and $4.0 \%(\mathrm{w} / \mathrm{v})$ were inoculated and the reaction followed. Thiosulphate oxidation was not inhibited by $4 \%$ $(w / v)$ sodium thiosulphate, although the time required for complete oxidation increased with concentration of thiosulphate. The decrease in $\mathrm{pH}$ value was delayed with the higher concentrations of thiosulphate, though ultimately it fell to less than $\mathrm{pH} \mathbf{2 \cdot 0}$ with all concentrations. (Starkey noted a similar phenomenon with Th. thiooxidans.) Tetrathionate was formed during thiosulphate oxidation at each concentration but disappeared before the cultures became sterile. Elementary sulphur formation was observed at each concentration, and was greater the higher the concentration. At the end of the incubation, the sulphur was present predominantly as sulphate at each concentration.

Tetrathionate oxidation. The finding that tetrathionate was an intermediate product of thiosulphate oxidation by $T h$. concretivorus made it desirable to examine its ability to oxidize tetrathionate. Quite high concentrations of tetrathionate were produced as an intermediate from thiosulphate, but the tetrathionate so formed was quickly oxidized further to sulphate and free sulphuric acid.

Medium 5, in which $\mathbf{0 . 5} \%(\mathrm{w} / \mathrm{v})$ potassium tetrathionate replaced thiosulphate, was inoculated with this strain, but, despite repeated attempts, neither growth nor oxidation of the tetrathionate occurred. As growth, tetrathionate formation and oxidation occurred in medium 5 when potassium thiosulphate replaced sodium thiosulphate, the absence of growth with potassium tetrathionate cannot be attributed to an absence of sodium ions. The inability of this organism to oxidize tetrathionate, despite its destruction by cultures in thiosulphate medium, is hard to understand, and no satisfactory reconciliation of the two observations can be made at present.

Oxidation of elementary sulphur. The method of oxidation of elementary sulphur by this organism was studied by Parker (1945). The sole product of oxidation in the presence of excess sulphur was sulphuric acid which reached concentrations of over $5 \%(\mathrm{w} / \mathrm{v})$.

$\mathrm{H}_{2} \mathrm{~S}$ oxidation. Parker (1945) reported that this organism did not utilize $\mathrm{H}_{2} \mathrm{~S}$ when cultures were exposed to air containing $1 \%(\mathrm{v} / \mathrm{v}) \mathrm{H}_{2} \mathrm{~S}$. In the present work the organism was inoculated into liquid mineral salt medium containing no oxidizable form of sulphur and incubated in air containing 200 p.p.m. $\mathrm{H}_{2} \mathrm{~S}$; initial $\mathrm{pH}$ value of medium $4 \cdot 5$. The results of analyses during incubation are shown in Table 4.

Metabolism was indicated by the continuous viable count throughout the period of incubation and was accompanied by a rapid drop in $\mathrm{pH}$ value from 4.5 to 1.8 in the inoculated flasks. The increase in the total sulphur content of the inoculated compared with the sterile flasks shows that $\mathrm{H}_{2} \mathrm{~S}$ was utilized. The end-product of oxidation was mainly sulphuric acid, but the presence of a small amount of elementary sulphur towards the end of the incubation period in the inoculated flasks, and its absence from the controls, suggested that sulphur was first formed and then oxidized. Thiosulphates and polythionates were not detected at any stage of the incubation. The growth of the 
organism in air containing 200 p.p.m. $\mathrm{H}_{2} \mathrm{~S}$ compared with its lack of growth in $1 \%(\mathrm{v} / \mathrm{v}) \mathrm{H}_{2} \mathrm{~S}$ suggests that the higher concentration was toxic.

Table 4. Oxidation of $\mathrm{H}_{2} \mathrm{~S}$ by Thiobacillus concretivorus

Cultures in medium 5 without thiosulphate, but with an atmosphere of air containing 200 p.p.m. $\mathrm{H}_{2} \mathrm{~S}$ were analysed at intervals after inoculation.

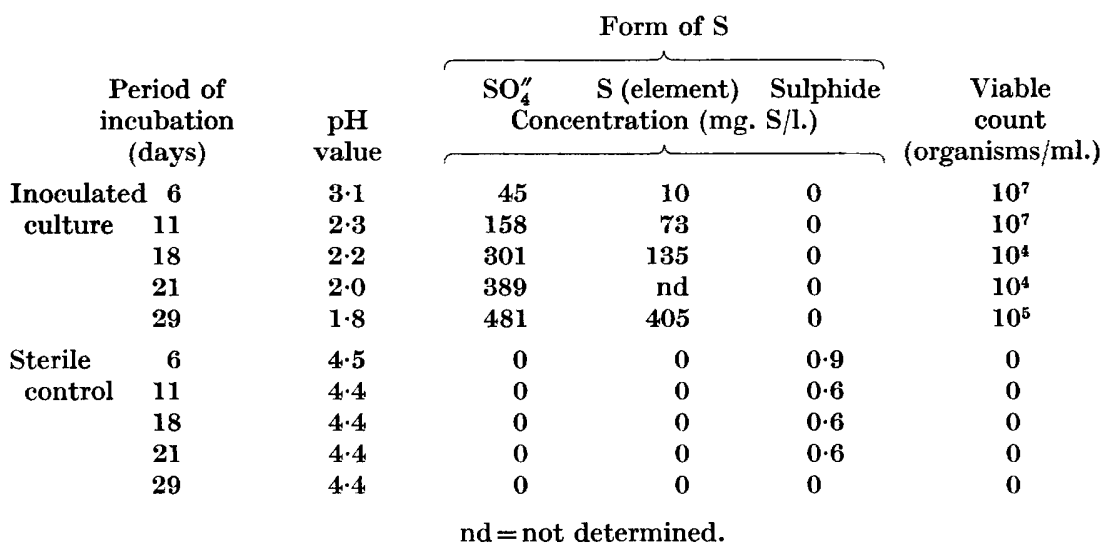

Thiobacillus thiooxidans

Thiosulphate oxidation. The route of oxidation of thiosulphate by this organism was described by Waksman \& Starkey (1923). Since tetrathionate was detected during the oxidation of thiosulphate by $T h$. concretivorus, a more detailed examination of its oxidation by $T h$. thiooxidans was made.

Table 5. Oxidation of thiosulphate by Thiobacillus thiooxidans

Cultures in medium 5 were analysed at intervals after inoculation.

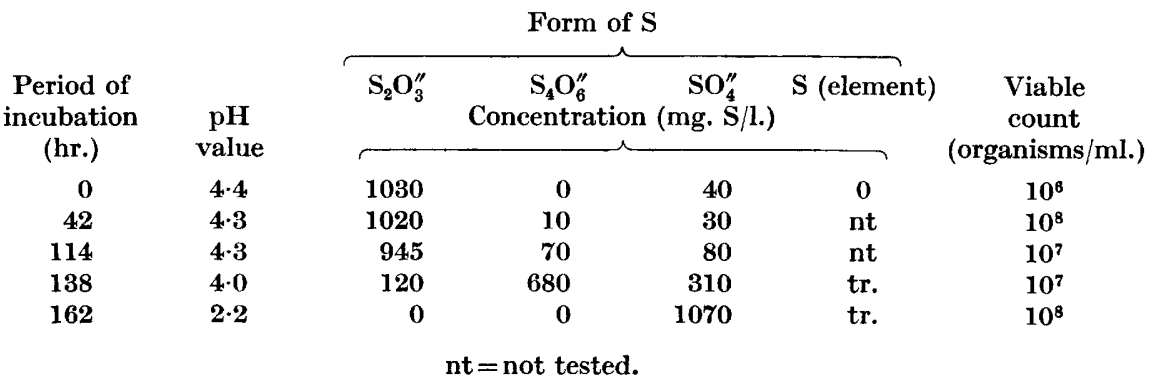

The results given in Table 5 show that during the destruction of thiosulphate, tetrathionate and sulphate were formed, but that there was little change in $\mathrm{pH}$ value until thiosulphate had completely disappeared. Tetrathionate was only found during a period of $24 \mathrm{hr}$. at the fifth to sixth day of incubation. After the complete disappearance of thiosulphate, tetrathionate was converted to sulphate with a sharp drop in $\mathrm{pH}$ value. 
The effect of concentration of thiosulphate on the course of reaction was studied in the manner described for $T h$. concretivorus. Table 6 records that, as noted by Starkey, the time taken for the $\mathrm{pH}$ value to decrease increases with concentration of thiosulphate. Thiosulphate was completely oxidized in media containing concentrations of $0.5 \%(\mathrm{w} / \mathrm{v})$ and $1 \%(\mathrm{w} / \mathrm{v})$, but with concentra-

Table 6. Effect of thiosulphate concentration on the oxidation of thiosulphate by Thiobacillus thiooxidans

Cultures in medium 5, containing various concentrations of sodium thiosulphate were analysed at intervals after inoculation.

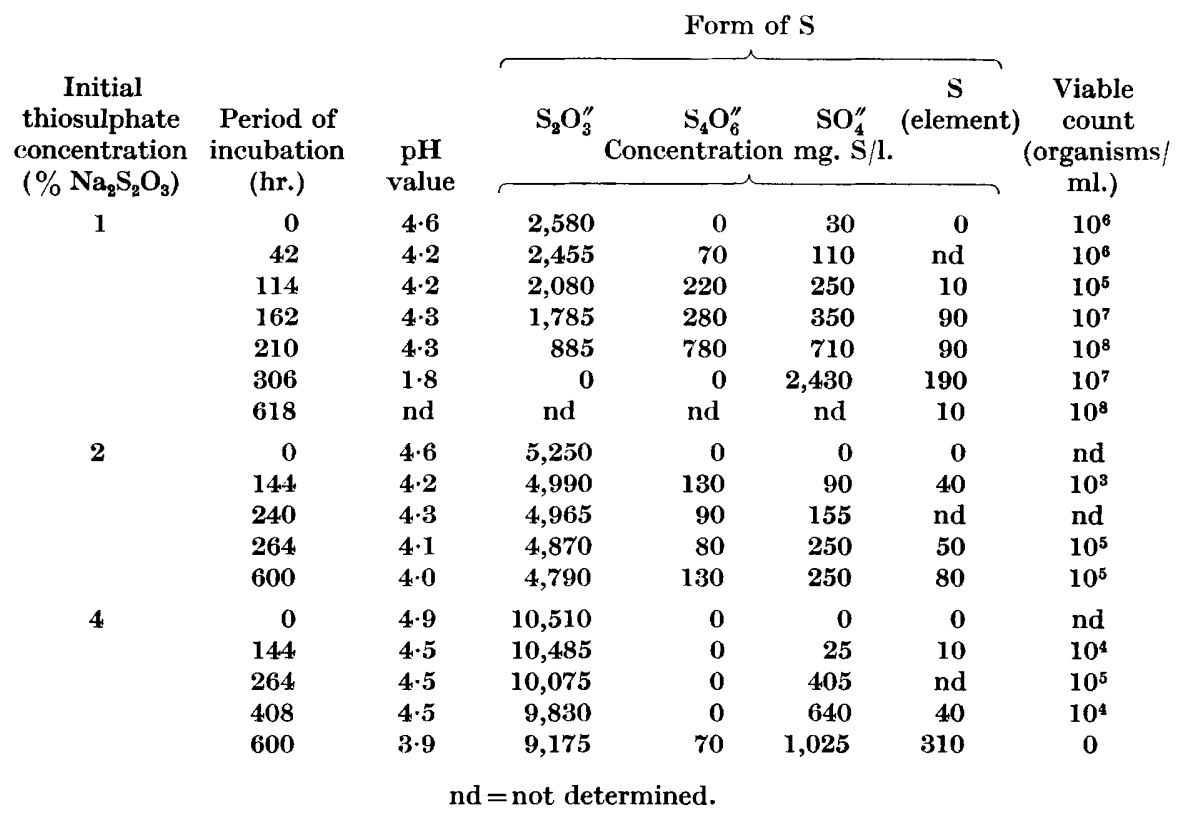

tions of $2 \%(\mathrm{w} / \mathrm{v})$ and $4 \%(\mathrm{w} / \mathrm{v})$, only about one-tenth was oxidized, even after 25 days' incubation. The low viable counts indicate that the higher concentrations of thiosulphate exerted an inhibitory effect. Tetrathionate was found, but the amount produced was less with the higher concentrations of thiosulphate. With a $1.0 \%(\mathrm{w} / \mathrm{v})$ thiosulphate the course of oxidation was similar to that described for $0.5 \%(\mathrm{w} / \mathrm{v})$; thiosulphate was first oxidized to tetrathionate and sulphate with little change in $\mathrm{pH}$ value. In this case, however, tetrathionate was detectable during a much longer period (168 hr.). It reached a maximum concentration when all thiosulphate had been oxidized, and was then converted to sulphate with rapid decrease in $\mathrm{pH}$ value. Proportionately much more elementary sulphur was formed from $1 \%$ than from $0.5 \%$ thiosulphate, suggesting that tetrathionate was partly oxidized to acid before the complete disappearance of thiosulphate. The low and diminishing tetrathionate/sulphate ratio during the period of thiosulphate destruction supports this view. 
Tetrathionate oxidation. Medium 5, in which $0.5 \%(\mathrm{w} / \mathrm{v})$ potassium tetrathionate replaced thiosulphate, was repeatedly inoculated, but neither growth nor tetrathionate oxidation could be established. With this organism, like $T h$. concretivorus, it is difficult to understand its inability to metabolize tetrathionate as a primary source of sulphur, while the tetrathionate formed during oxidation of thiosulphate media is rapidly destroyed.

Oxidation of elementary sulphur by $T h$. thiooxidans was studied by Lipman, Waksman \& Joffe (1921), Waksman (1922 $a, b)$, Waksman \& Starkey (1923), Starkey (1925). Our re-examination of this oxidation process in medium 6 confirmed the findings of the above authors that sulphur is converted directly to free sulphuric acid without the formation of any intermediate products.

$\mathrm{H}_{2} \mathrm{~S}$ oxidation. Th. thiooxidans was inoculated into medium 5 without thiosulphate, and incubated in air containing $\mathrm{H}_{2} \mathrm{~S}$. A viable count was obtained even after 48 days incubation, by which time the $\mathrm{pH}$ value had decreased to 2.2. $\mathrm{H}_{2} \mathrm{~S}$ was oxidized as shown by the increase in total dissolved sulphur from 0 to $472 \mathrm{mg}$./l.; the main product was sulphuric acid. As with $T$. concretivorus, a little elementary sulphur accumulated towards the end of the incubation period; this suggests that the oxidation goes through elementary sulphur. The amount of sulphur formed by $T h$. thiooxidans was much less than that formed by $T h$. concretivorus. The ability of $T h$. thiooxidans to oxidize $\mathrm{H}_{2} \mathrm{~S}$ has been the subject of contradictory statements in the literature, but the present experiments definitely establish its ability to utilize $\mathrm{H}_{2} \mathrm{~S}$ under the conditions described. Its mode of oxidizing sulphide appears to be identical with that of Th. concretivorus.

\section{Thiobacillus X}

Thiosulphate oxidation. Oxidation of thiosulphate by two strains was studied. As they oxidized thiosulphate in essentially the same way, results for one strain only (X 44) are given in Fig. 1. The final products of oxidation were tetrathionate, sulphate, free sulphuric acid, and very small amounts of free sulphur and pentathionate; the $\mathrm{pH}$ value fell from $6 \cdot 6$ to $3 \cdot 3$. The oxidation occurred in three stages. During the first $45 \mathrm{hr}$. there was a slow increase in sulphate and fall in $\mathrm{pH}$ value, but no polythionates could be detected, nor was any free sulphur present. About $10 \%$ of the thiosulphate was oxidized during this period and the bacterial count increased from $10^{6}$ to $10^{8}$ organisms $/ \mathrm{ml}$. In the next $24 \mathrm{hr}$. the remaining $90 \%$ of the thiosulphate was oxidized, the bacterial count increased to $9 / \mathrm{ml}$. and there was little fall in $\mathrm{pH}$ value. There was accelerated production of sulphate and rapid production of polythionate (almost entirely tetrathionate). The third stage immediately followed the disappearance of thiosulphate. The $\mathrm{pH}$ value decreased from $6 \cdot 6$ to $c$. 3 , tetrathionate concentration decreased and the sulphate concentration increased (although more slowly than in the previous period). A thin pellicle, presumably of sulphur, became visible. This third stage occupied $27 \mathrm{hr}$., during which the bacterial count fell from $10^{9}$ to $10^{7}$ organisms $/ \mathrm{ml}$. Following the sharp decrease in $\mathrm{pH}$ value there was a further slow decrease to an ultimate value of $\mathrm{pH} \mathrm{3.0,}$ accompanied by a slow decrease in polythionate and an increase in sulphate 
concentration. The bacterial count decreased and the culture became sterile after $120 \mathrm{hr}$., although a considerable amount of polythionate remained. The inability of this organism to carry tetrathionate oxidation to completion suggests that it is intolerant of $\mathrm{pH}$ values less than $3 \cdot 0$. This point was examined by adding a suspension of organisms to sterile saline buffered to different $\mathrm{pH}$ values; it was found that on subculture into medium 2 , organisms exposed to

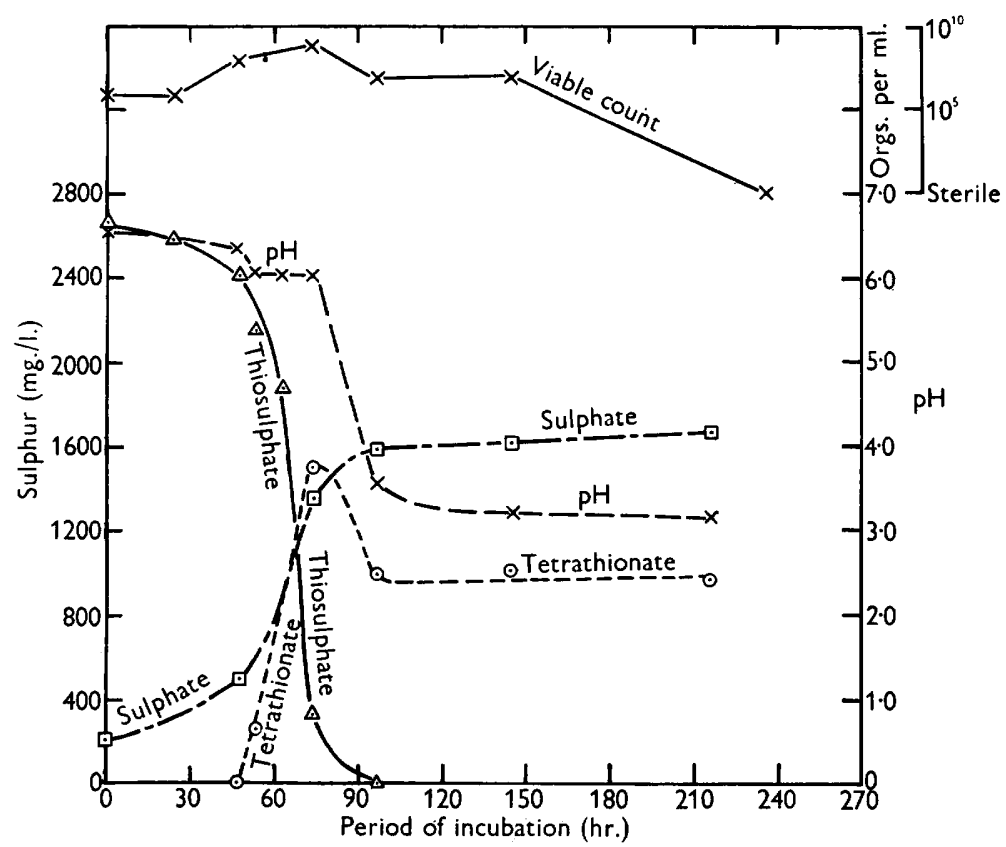

Fig. 1. Oxidation of thiosulphate by Thiobacillus $X$ (strain X44). Cultures in medium 2 containing $1 \%(\mathrm{w} / \mathrm{v}) \mathrm{Na}_{2} \mathrm{~S}_{2} \mathrm{O}_{3}$ were analysed at intervals after inoculation.

$\mathrm{pH}$ values less than $\mathbf{3} \cdot \mathbf{0}$ for $\mathbf{3 0} \mathrm{min}$. failed to grow. Further support for this view was obtained by making the usual analyses in a thiosulphate culture in which the $\mathrm{pH}$ value, by continuous readjustment, was prevented from becoming less than $4 \cdot 7$ during the whole period of incubation. Under these conditions tetrathionate was completely converted to sulphate, and the rate of increase of sulphate concentration following thiosulphate disappearance was much greater than in the unadjusted culture. Whereas the unadjusted culture was sterile within 5 days of completion of thiosulphate oxidation, a count of $10^{7}$ viable organisms $/ \mathrm{ml}$. was found 12.5 days after thiosulphate oxidation had ceased in the adjusted culture.

Tetrathionate oxidation. Tetrathionate was formed as an intermediate in thiosulphate oxidation, and was subsequently converted partially to sulphate and free acid. The strain used was inoculated into medium 2, containing $0.5 \%(\mathrm{w} / \mathrm{v})$ tetrathionate, instead of thiosulphate, and analysed at intervals as before (Table 7). The strain grew well and oxidized tetrathionate rapidly, the final products being sulphate and some pentathionate; some tetrathionate 
remained unoxidized. The oxidation was accompanied by a decrease in $\mathrm{pH}$ value from $6 \cdot 7$ to $3 \cdot 3$. Within $30 \mathrm{hr}$. after inoculation, rapid oxidation of tetrathionate began, and its destruction was associated with rapid increase in sulphate concentration and a sharp decrease in $\mathrm{pH}$ value from $6 \cdot 6$ to $3 \cdot 5$. A little thiosulphate appeared between 20 and $45 \mathrm{hr}$. but later disappeared.

Table 7. Oxidation of tetrathionate by Thiobacillus X (strain X44)

Cultures in medium 2 with potassium tetrathionate instead of thiosulphate were analysed at intervals after inoculation.

\begin{tabular}{|c|c|c|c|c|c|c|c|}
\hline \multirow[b]{2}{*}{$\begin{array}{c}\text { Period of } \\
\text { incubation } \\
(\mathrm{hr} .)\end{array}$} & \multirow[b]{2}{*}{$\underset{\text { value }}{\mathrm{pH}}$} & \multicolumn{5}{|c|}{ Form of $S$} & \multirow{2}{*}{$\begin{array}{c}\text { Viable } \\
\text { count } \\
\text { (organisms } / \mathrm{ml} \text {.) }\end{array}$} \\
\hline & & $\mathrm{S}_{2} \mathrm{O}_{3}^{\prime \prime}$ & $\begin{array}{l}\mathrm{S}_{4} \mathrm{O}_{6}^{\prime \prime} \\
\text { Conce }\end{array}$ & $\begin{array}{r}\mathrm{S}_{5} \mathrm{O}_{6}^{\prime} \\
\text { ratior }\end{array}$ & $\begin{array}{l}\mathrm{SOO}_{4}^{\prime \prime} \\
\mathrm{S} / \mathrm{l}\end{array}$ & $\begin{array}{c}\mathrm{S} \\
\text { (element) }\end{array}$ & \\
\hline 20 & $6 \cdot 6$ & 5 & 2100 & 0 & 80 & 0 & $10^{6}$ \\
\hline 45 & $6 \cdot 2$ & 55 & 1810 & 0 & 380 & tr. & $10^{8}$ \\
\hline 68 & $\mathbf{3 \cdot 9}$ & 0 & 1510 & 0 & 590 & 10 & $10^{8}$ \\
\hline 74 & $3 \cdot 8$ & 0 & nd & nd & nd & nd & $10^{7}$ \\
\hline 93 & $3 \cdot 6$ & 0 & 1540 & 0 & 600 & tr. & $10^{7}$ \\
\hline 141 & $3 \cdot 6$ & 0 & 1560 & 0 & 660 & tr. & $10^{6}$ \\
\hline 237 & $3 \cdot 5$ & 0 & 1050 & 570 & 640 & tr. & $10^{3}$ \\
\hline 573 & $3 \cdot 3$ & 45 & 1150 & 170 & 850 & 20 & Sterile \\
\hline \multicolumn{8}{|l|}{ Control } \\
\hline 45 & $6 \cdot 7$ & 5 & 2080 & 0 & 140 & 0 & Sterile \\
\hline 573 & $6 \cdot 5$ & 205 & 1290 & 540 & 200 & 0 & Sterile \\
\hline
\end{tabular}

When the $\mathrm{pH}$ value had decreased to $3 \cdot 5$, oxidation of tetrathionate, sulphate formation, and further fall in $\mathrm{pH}$ value all practically ceased. The bacterial count decreased shortly after and eventually the culture became sterile. These results are essentially the same as those described for the third stage of thiosulphate oxidation by this organism. The appearance of pentathionate after c. 10 days incubation may have been due to a chemical conversion of tetrathionate after bacterial activity had ceased, as the viable count had then fallen to $10^{3}$ organisms $/ \mathrm{ml}$. The presence of pentathionate in the sterile control after 24 days incubation indicated that chemical conversion of tetrathionate to pentathionate could occur. These results confirm the ability of this organism to oxidize tetrathionate with the formation of sulphate and acid.

Oxidation of elementary sulphur. The strain was inoculated into medium 2 containing $10 \mathrm{~g}$. sulphur/l. in place of thiosulphate and analysed at intervals. The organism grew with elementary sulphur which was oxidized directly to sulphuric acid as indicated by an increase in sulphate and a decrease in pH value. No immediate products were detected at any stage of the incubation.

The rate of oxidation, indicated by the rate of acid formation, during the period of maximum activity of this organism was only about $10 \%$ of that exhibited by $T h$. concretivorus and $T h$. thiooxidans. The oxidation of elementary sulphur by this organism also differed from those organisms, in that the amount of acid formed before the culture became sterile and oxidation ceased was less. Only $0.061 \%(\mathrm{w} / \mathrm{v}) \mathrm{SO}_{4}^{\prime \prime}$ was formed by Thiobacillus $X$, compared with values 
between 1 and $10 \%$ with the two high acid-formers; the $\mathrm{pH}$ value in this case fell only to $\mathbf{3 \cdot 1}$, whereas with the other two organisms it became less than $\mathbf{1} \cdot \mathbf{0}$.

$\mathrm{H}_{2} \mathrm{~S}$ oxidation. Medium 2 lacking any form of oxidizable sulphur was inoculated and incubated in air containing 200 p.p.m. of $\mathrm{H}_{2} \mathrm{~S}$. A high viable count was maintained for 24 days; thereafter the count decreased and the culture was sterile after 47 days. Sterility was again associated with decrease in $\mathrm{pH}$ value to $\mathbf{3 \cdot 0}$, as happened with elementary sulphur and thiosulphate. During the early stage of oxidation only sulphate sulphur increased (owing to the formation of sulphuric acid), but towards the end of the incubation period, when the viable count had decreased, there was also an increase in elementary sulphur. This suggests that the conversion of $\mathrm{H}_{2} \mathrm{~S}$ to sulphate was through the intermediate formation of elementary sulphur. There was no evidence that thiosulphate or polythionates were formed at any stage.

\section{Thiobacillus thioparus}

Thiosulphate oxidation. The strain Thiobacillus $X$ was described (Parker, 1947) as $T h$. thioparus-like principally because of $(a)$ its ability to form a pellicle when grown with thiosulphate in liquid culture in a test tube, $(b)$ its very slow oxidation of elementary sulphur and $(c)$ the fact that growth ceased when the $\mathrm{pH}$ value fell to 3-4. A detailed examination of an authentic strain of $T h$. thioparus was therefore made for comparison with Thiobacillus $X$. Medium 2, containing $1 \%(\mathrm{w} / \mathrm{v})$ sodium thiosulphate, was inoculated from a fresh slope culture, and observations were made as before (Table 8 ). The

Table 8. Oxidation of thiosulphate by Thiobacillus thioparus

Cultures in medium 2 were analysed at intervals after inoculation.

\begin{tabular}{|c|c|c|c|c|c|}
\hline \multirow{2}{*}{$\begin{array}{c}\text { Period of } \\
\text { incubation } \\
\text { (hr.) }\end{array}$} & \multirow{2}{*}{$\begin{array}{c}\mathrm{pH} \\
\text { value }\end{array}$} & \multicolumn{3}{|c|}{ Form of $\mathrm{S}$} & \multirow{2}{*}{$\begin{array}{c}\text { Viable } \\
\text { count } \\
\text { (organisms } / \mathrm{ml} \text {.) }\end{array}$} \\
\hline & & \multicolumn{3}{|c|}{ Concentration mg. S/l. } & \\
\hline 0 & $6 \cdot 6$ & 2670 & 40 & 0 & $10^{6}$ \\
\hline 87 & $6 \cdot 5$ & 2605 & 110 & $\mathbf{0}$ & $10^{7}$ \\
\hline 137 & $6 \cdot 4$ & 2355 & 290 & 80 & $10^{7}$ \\
\hline 186 & $6 \cdot 3$ & 1005 & 1008 & 680 & $10^{7}$ \\
\hline 208 & $6 \cdot 3$ & 570 & 1260 & 870 & $10^{7}$ \\
\hline 257 & 6.0 & 0 & 1630 & 1090 & $10^{7}$ \\
\hline 329 & $5 \cdot 5$ & o & 1660 & 1040 & $10^{7}$ \\
\hline 521 & 4.9 & 0 & 1720 & 980 & $10^{6}$ \\
\hline 689 & $4 \cdot 7$ & 0 & 1720 & 970 & $10^{5}$ \\
\hline
\end{tabular}

ultimate products of oxidation of thiosulphate were sulphate and elementary sulphur; polythionates were not detected at any stage of incubation. A decrease in $\mathrm{pH}$ value from 6.6 to 4.7 indicated that some of the sulphate existed as $\mathrm{H}_{2} \mathrm{SO}_{4}$. During the oxidation of thiosulphate, sulphate and sulphur were formed in the ratio of 6 to 4 , and the $\mathrm{pH}$ value decreased from $6 \cdot 5$ to $6 \cdot 0$. This supports the observations of Starkey (1935a). After the complete disappearance of thiosulphate, there was a further decrease in $\mathrm{pH}$ value to 4.7 , accompanied 
by a decrease in the amount of elementary sulphur and a corresponding rise in sulphate concentration. This confirmed the suggestion of Starkey (1935a) that the decrease in $\mathrm{pH}$ value which follows the disappearance of thiosulphate is due to oxidation of sulphur. The continued viability of the culture for at least 18 days after the disappearance of the thiosulphate, when elementary sulphur was the only available sulphur source, suggests that this conversion of elementary sulphur to sulphuric acid is biological. The slow oxidation of elementary sulphur eventually ceased when the $\mathrm{pH}$ value dropped to $4 \cdot 5$. This occurs when only a small proportion of the sulphur first formed had been converted into sulphuric acid. This organism did not produce tetrathionate from thiosulphate.

Tetrathionate oxidation. Medium 2 without thiosulphate, but containing $0.5 \%(\mathrm{w} / \mathrm{v})$ tetrathionate, was inoculated with $T$ h. thioparus. After 24 days of incubation less tetrathionate had disappeared from the incubated flasks than from the sterile controls, although a high viable count in the inoculated flask was always found. A decrease in $\mathrm{pH}$ value from 6.6 to 5.9 in the inoculated flasks, compared with a stable $\mathrm{pH} 6 \cdot 4$ in the sterile control, suggested that oxidation of some sulphur compound had occurred. The presence of $205 \mathrm{mg}$. thiosulphate sulphur/l. in the sterile controls suggests that thiosulphate was formed by chemical decomposition of tetrathionate and then oxidized by the organisms. It seems probable that this organism does not oxidize tetrathionate.

Oxidation of elementary sulphur. Starkey (1934a) stated that Th. thioparus oxidizes elementary sulphur. Re-examination of the strain used during the present work confirmed that finding. Sulphur was oxidized to sulphuric acid without the formation of detectable intermediate products. The rate of oxidation was similar to that of Thiobacillus $X$ and was much less than for Th. thiooxidans and $T h$. concretivorus; the amount of sulphur oxidized was also much less $(650 \mathrm{mg}$./I.). With this organism oxidation ceased when the $\mathrm{pH}$ value dropped to $4 \cdot 4$, as happened with thiosulphate.

$\mathrm{H}_{2} \mathrm{~S}$ oxidation. Th. thioparus was inoculated into media $1,2,3$ and 4, containing no oxidizable form of sulphur, and incubated in air containing 200 p.p.m. $\mathrm{H}_{2} \mathrm{~S}$. No growth occurred, so this organism cannot oxidize hydrogen sulphide. Starkey did not specifically mention gaseous hydrogen sulphide, but stated that when examined by him the organism did not utilize sulphides. Beijerinck (1904) recorded that both calcium and hydrogen sulphides were utilized by the original culture of $T h$. thioparus isolated by Nathansohn.

\section{Thiobacillus novellus}

Thiosulphate oxidation. The organism was examined in the usual way, using medium 2 with $1 \%(\mathrm{w} / \mathrm{v})$ thiosulphate. The rate of oxidation by this strain used was very much slower than with any of the previous four organisms; less than $20 \%$ of the thiosulphate was oxidized in 40 days. The only product of oxidation was sulphate, and its formation was accompanied by a slow decrease in $\mathrm{pH}$ value; no tetrathionate was formed. The bacterial count indicated a low degree of bacterial activity. These results confirm Starkey's observations $(1935 a)$ on this organism. 
Tetrathionate oxidation. When medium 2, without thiosulphate, but containing $0.5 \%(\mathrm{w} / \mathrm{v})$ potassium tetrathionate, was inoculated with this organism it became sterile within 15 days, indicating inability to survive or grow with tetrathionate.

Oxidation of elementary sulphur. Inoculation into medium 2 with elementary sulphur in place of thiosulphate indicated that, while viable organisms could be recovered 32 days later, no detectable oxidation of sulphur to sulphate took place. This agrees with Starkey's finding $(\mathbf{1 9 3 5} b)$ that the organism does not oxidize free sulphur.

$\mathrm{H}_{2} \mathrm{~S}$ oxidation. As Starkey found, the organism did not oxidize hydrogen sulphide when inoculated into medium 2 or 4 with hydrogen sulphide as the sole source of sulphur.

$$
\text { ' } M \text { ' cultures }
$$

Thiosulphate oxidation. Three strains of this group, M.20, M.77 and M.79, were selected for detailed study because they were the best oxidizers of thiosulphate. As the course of the reaction with the three strains was similar the results from one strain only (M.79) are shown in Table 9.

Table 9. Oxidation of thiosulphate by ' $M$ ' organism, strain $M .79$

Cultures in medium 2 were analysed at intervals after inoculation.

\begin{tabular}{|c|c|c|c|c|c|c|c|c|c|}
\hline \multirow[b]{2}{*}{$\begin{array}{c}\text { Period of } \\
\text { incubation } \\
\text { (hr.) }\end{array}$} & \multirow{2}{*}{$\underset{\text { value }}{\mathrm{pH}}$} & \multicolumn{6}{|c|}{ Form of $\mathrm{S}$} & \multirow[b]{2}{*}{$\begin{array}{c}\text { Total S } \\
\text { (by addition) }\end{array}$} & \multirow{2}{*}{$\begin{array}{c}\text { Viable count } \\
\text { (organisms/ml.) }\end{array}$} \\
\hline & & $\mathrm{S}_{2} \mathrm{O}_{3}^{\prime \prime}$ & $\mathrm{S}_{4} \mathrm{O}_{6}^{\prime \prime}$ & $\mathrm{S}_{5} \mathrm{O}_{6}^{\prime \prime}$ & $\begin{array}{r}\mathrm{S}_{3} \mathrm{O}_{6}^{\prime \prime} \\
\text { tration }\end{array}$ & $\mathrm{SO}_{4}^{\prime \prime}$ & $\mathrm{S}$ (element) & & \\
\hline 0 & $6 \cdot 6$ & 2640 & 0 & 0 & 0 & 80 & 0 & 2720 & nd \\
\hline 22 & $6 \cdot 6$ & 2630 & 0 & nd & nd & $\begin{array}{l}00 \\
100\end{array}$ & 0 & nd & $\begin{array}{l}\mathrm{nu} \\
10^{5}\end{array}$ \\
\hline 46 & $6 \cdot 5$ & nd & nd & nd & nd & nd & nd & nd & nd \\
\hline 71 & $6 \cdot 6$ & 2440 & nd & nd & nd & 150 & nd & nd & $10^{6}$ \\
\hline 166 & $7 \cdot 3$ & 1255 & 880 & 470 & 0 & 410 & 10 & 3025 & $10^{7}$ \\
\hline 238 & $7 \cdot 5$ & 1020 & 1000 & 330 & 0 & 360 & 20 & 2730 & $10^{7}$ \\
\hline 384 & $7 \cdot 5$ & 815 & 1680 & 30 & 180 & nd & 20 & nd & $10^{5}$ \\
\hline 502 & $7 \cdot 8$ & 535 & 1230 & 330 & 240 & 420 & 30 & 2785 & $10^{6}$ \\
\hline 695 & $7 \cdot 6$ & 395 & nd & nd & nd & nd & nd & nd & $10^{6}$ \\
\hline 1367 & $\dot{7} \cdot 0$ & 365 & 490 & 590 & 460 & $7 \cdot 80$ & 75 & 2755 & $10^{7}$ \\
\hline 1775 & 6.8 & nd & nd & nd & nd & nd & nd & nd & nd \\
\hline
\end{tabular}

Strain M.79 destroyed $87 \%$ of the thiosulphate during 57 days. The products of oxidation after 56 days of incubation were a mixture of tri-, tetraand pentathionate, some sulphate and a little elementary sulphur. The $\mathrm{pH}$ value at first increased from $6 \cdot 6$ to $7 \cdot 8$ and then fell slowly to $7 \cdot 0$. The bacterial count remained high throughout the period of incubation. There was a rapid disappearance of thiosulphate early in the incubation, becoming slower after c. 8 days and stopping before all the thiosulphate had disappeared. The period of rapid thiosulphate oxidation was associated with the appearance of a considerable amount of tetrathionate and a sharp increase in $\mathrm{pH}$ value; this increase distinguishes these strains from those organisms already described. There was a slight increase in sulphate concentration and some pentathionate formation, but no elementary sulphur was formed in this stage. The subsequent stage of slower thiosulphate oxidation was associated with a slow decrease in 
tetrathionate, the formation of tri- and pentathionate, and a slow increase in sulphate. Only minute amounts of elementary sulphur were formed, even after prolonged incubation.

Tetrathionate oxidation. The ' $\mathrm{M}$ ' strains produced tetrathionate from thiosulphate, but showed little ability to destroy it. They were inoculated into medium 2 in which $0.5 \%(\mathrm{w} / \mathrm{v})$ tetrathionate replaced thiosulphate, but could only be recovered in small numbers after 14 days.

Oxidation of elementary sulphur. Strain M.79 was incubated in medium 2 with elementary sulphur in place of thiosulphate. It persisted in the medium for at least 32 days. Although no change occurred in the $\mathrm{pH}$ value of the medium, there was a very slight increase (from 49 to $106 \mathrm{mg}$./1.) in the sulphate content, which suggests that this strain could oxidize sulphur very slowly. The $\mathrm{pH}$ value did not decrease, probably because the amount of acid formed was too small to affect the phosphate-buffered medium. The rate of sulphate formation was lower than with Thiobacillus $X$ and $T h$. thioparus.

$\mathrm{H}_{2} \mathrm{~S}$ oxidation. Although these ' $M$ ' strains remained viable for periods up to 44 days when inoculated into medium 4 with hydrogen sulphide as source of sulphur, there was no evidence of hydrogen sulphide oxidation.

\section{Thiobacillus B (Waksman) and strains ' $T$ ' and ' $K$ ' (Trautwein)}

Thiosulphate oxidation. Thiobacillus $B$ (Waksman) and strains ' $T$ ' and ' $K$ ' (Trautwein) were examined in medium 2. The results confirm Starkey's observations (1935a) that these cultures oxidize thiosulphate primarily with the formation of alkali and tetrathionate, accompanied by an increase in $\mathrm{pH}$ value. This was followed later by the appearance of trithionate, pentathionate and some sulphate, with a slow decrease in $\mathrm{pH}$ value.

Tetrathionate oxidation. These strains were similarly examined to determine their ability to survive in medium 2 in which $0.5 \%(\mathrm{w} / \mathrm{v})$ tetrathionate replaced thiosulphate. All three strains were recovered after 15 days incubation, but since the $\mathrm{pH}$ value of the cultures did not differ from that of the control, it seems unlikely that they were capable of oxidation of tetrathionate.

Oxidation of elementary sulphur. These strains were inoculated into medium 2 with elementary sulphur in place of the thiosulphate. Strains ' $B$ ' and ' $T$ ' survived for 32 days, but strain ' $K$ ' was not viable after 7 days. There was no analytical evidence to suggest that any of the strains oxidized sulphur to sulphate, which confirms Starkey's findings (1934a). Their behaviour is thus similar to that of $T h$. novellus in this respect.

$\mathrm{H}_{2} \mathrm{~S}$ oxidation. Thiobacillus $B$ and strains ' $\mathrm{T}$ ' and ' $\mathrm{K}$ ' were inoculated into medium 4 with hydrogen sulphide as source of sulphur. Cultures of Thiobacillus $B$ and strain ' $K$ ' became sterile within $24 \mathrm{hr}$. It was earlier suggested that $\mathbf{H}_{2} \mathrm{~S}$ in high concentration is toxic to $T h$. concretivorus and the rapid death of the cultures of Thiobacillus $B$ and of strain ' $\mathrm{K}$ ' suggests that $\mathrm{H}_{2} \mathrm{~S}$ may be toxic to these organisms also. Strain ' $T$ ', however, grew. Parker (1947) showed that $\mathrm{H}_{2} \mathrm{~S}$ in air, passed over an alkaline solution, forms small amounts of thiosulphate and polythionate. It seems probable that a small amount of thiosulphate was formed chemically, in the ' $T$ ' culture medium, and that this 
enabled strain ' $T$ ' to grow. With Thiobacillus $B$ and strain ' $K$ ', however, the toxic effect of $\mathrm{H}_{2} \mathrm{~S}$ would appear to have prevented growth, despite the presence of available thiosulphate.

\section{DISCUSSION \\ Oxidation of thiosulphate}

Thiosulphate is the form of oxidizable sulphur most widely utilized by Thiobacillus spp.; the nine strains studied all oxidized thiosulphate readily. The course of oxidation, however, varies with the strain, four different courses being observed.

(1) Thiosulphate is oxidized by $T h$. concretivorus and $T h$. thiooxidans first to tetrathionate and sulphate. In a further stage the tetrathionate is oxidized to sulphate and free sulphuric acid according to equations such as

$$
\begin{gathered}
6 \mathrm{Na}_{2} \mathrm{~S}_{2} \mathrm{O}_{3}+5 \mathrm{O}_{2} \rightarrow 4 \mathrm{Na}_{2} \mathrm{SO}_{4}+2 \mathrm{Na}_{2} \mathrm{~S}_{4} \mathrm{O}_{6} \quad \text { (first stage), } \\
2 \mathrm{Na}_{2} \mathrm{~S}_{4} \mathrm{O}_{6}+6 \mathrm{H}_{2} \mathrm{O}+7 \mathrm{O}_{2} \rightarrow 2 \mathrm{Na}_{2} \mathrm{SO}_{4}+6 \mathrm{H}_{2} \mathrm{SO}_{4} \quad \text { (second stage). }
\end{gathered}
$$

The production of free acid in the second stage explains the rapid decrease in $\mathrm{pH}$ value after the disappearance of thiosulphate.

Waksman \& Starkey (1923) stated that Th.thiooxidans oxidized thiosulphate directly to sulphate and sulphuric acid; the present examination revealed that there is an intermediate production of tetrathionate. Waksman \& Starkey (1923) only made observations at infrequent intervals, and Starkey (1934b), when examining this organism for polythionate formation, also only made observations after 7 days incubation, when $7 \%$ of the thiosulphate had been oxidized, and after 28 days, when the whole of it had disappeared. In view of the transient occurrence of the tetrathionate during incubation it is not surprising that its formation was overlooked.

Th. concretivorus differs from $T h$. thiooxidans in that the former oxidizes thiosulphate completely from initial concentrations up to $4 \%$, whereas $T h$. thiooxidans is markedly inhibited by $2 \%$ and almost completely inhibited by $4 \%$.

With $T h$. concretivorus in concentrations of 2 and $4 \%$ thiosulphate the decrease in $\mathrm{pH}$ value and the occurrence of the maximum tetrathionate concentration before all the thiosulphate has disappeared suggests that towards the end of the thiosulphate oxidation, thiosulphate and tetrathionate oxidation are taking place simultaneously. With the 2 and $4 \%$ concentrations, the amount of elementary sulphur formed is proportionately much greater than with the lower concentrations. The formation of $100 \mathrm{mg}$. S/l. after 26 days from the $4 \%$ concentration before complete disappearance of thiosulphate is also consistent with the simultaneous oxidation of thiosulphate and tetrathionate; the acid formed from tetrathionate oxidation could react with unchanged thiosulphate to precipitate sulphur. As a final stage the sulphur so formed may be oxidized to sulphuric acid as, with the 1.0 and $2 \%$ initial concentrations of thiosulphate, the concentration of sulphur at the end of the incubation period further decreased.

Oxidation by $T h$. thiooxidans in $2 \%$ thiosulphate, although less in extent, 
is similar in nature to that by $T h$. concretivorus at concentrations of 2 and $4 \%$. Over the whole period of observation tetrathionate and elementary sulphur could be detected; the sulphate showed a slow increase and the $\mathrm{pH}$ value a slow decrease. Although only a little thiosulphate was oxidized it would appear that thiosulphate and tetrathionate oxidation occurred simultaneously.

Thiosulphate oxidation by Thiobacillus $X$ appears also to occur in two stages according to equations such as (1) and (2) above. With this organism, however, the second stage does not go to completion; the culture becomes sterile at a $\mathrm{pH}$ value of $\mathbf{3 \cdot 0}$, although some tetrathionate remains unoxidized. The increase in sulphate without any tetrathionate accumulation at the beginning of the incubation, and the fact that the $\mathrm{pH}$ value does not increase during the rapid oxidation of thiosulphate in the second stage, may be because the two reactions occur simultaneously from the beginning of the incubation, although the formation of the tetrathionate oxidase would appear to be slower than that of the thiosulphate oxidase.

(2) Thiosulphate is oxidized by $T h$. thioparus to sulphate and elementary sulphur, followed by a slight and slow oxidation of the sulphur to sulphuric acid, with a decrease in $\mathrm{pH}$ value to $\mathbf{4 \cdot 3}$, according to equations such as (3) and (4):

$$
\begin{gathered}
5 \mathrm{Na}_{2} \mathrm{~S}_{2} \mathrm{O}_{3}+\mathrm{H}_{2} \mathrm{O}+4 \mathrm{O}_{2} \rightarrow 5 \mathrm{Na}_{2} \mathrm{SO}_{4}+\mathrm{H}_{2} \mathrm{SO}_{4}+4 \mathrm{~S}, \\
2 \mathrm{~S}+3 \mathrm{O}_{2}+2 \mathrm{H}_{2} \mathrm{O} \rightarrow 2 \mathrm{H}_{2} \mathrm{SO}_{4} .
\end{gathered}
$$

As with Thiobacillus $X$ the extent of acid formation appears to be limited by acid tolerance of the organisms; this was confirmed by examination of the $\mathrm{pH}$ tolerance of the organism in buffered saline. The first stage of this oxidation by $T h$. thioparus was described by Starkey (1935a); it was confirmed in the present work. Starkey also suggested that the decrease in $\mathrm{pH}$ value was probably due to oxidation of the sulphur first formed; this suggestion has been confirmed by the present work.

(3) Thiosulphate may be converted by $T h$. novellus directly to sulphate and sulphuric acid, with decrease in $\mathrm{pH}$ value according to an equation such as (5):

$$
\mathrm{Na}_{2} \mathrm{~S}_{2} \mathrm{O}_{3}+2 \mathrm{O}_{2}+\mathrm{H}_{2} \mathrm{O} \rightarrow \mathrm{Na}_{2} \mathrm{SO}_{4}+\mathrm{H}_{2} \mathrm{SO}_{4} \text {. }
$$

As with Thiobacillus $X$ and Th. thioparus, the amount of acid formed appears to be limited by the acid tolerance of the organism; this was confirmed by separate examination in buffered saline. The present observations confirm those of Starkey $(\mathbf{1 9 3 5} a)$ with regard to the route of thiosulphate oxidation by $T h$. novellus. It had been considered that the thiosulphate oxidation by Th. novellus was identical with that produced by $T h$. thiooxidans, but the present observations concerning the intermediate production of tetrathionate by $T h$. thiooxidans indicates a marked difference between the two organisms.

(4) Thiosulphate can also be converted to sulphate and tetrathionate, with an increase in $\mathrm{pH}$ value, according to an equation such as (6):

$$
2 \mathrm{Na}_{2} \mathrm{~S}_{2} \mathrm{O}_{3}+\mathrm{H}_{2} \mathrm{O}+\frac{1}{2} \mathrm{O}_{2} \rightarrow \mathrm{Na}_{2} \mathrm{~S}_{4} \mathrm{O}_{6}+2 \mathrm{NaOH} \text {, }
$$

followed by a further small conversion of tetrathionate to tri- and pentathionate, and a decrease in $\mathrm{pH}$ value, sometimes back to the initial value at 
inoculation. Oxidation in this way by the ' $T$ ' and ' $K$ ' strains of Trautwein and by Thiobacillus $B$ was described by Starkey (1935 $a$ ); the present results are in agreement with those observations. Starkey suggested that the conversion of tetra- to tri- and pentathionate was a purely chemical change; the findings of high viable counts throughout the incubation period in the present work suggests that the organisms may be involved. However, the detection of pentathionate in sterile controls of medium 2 containing tetrathionate instead of thiosulphate, indicates that pentathionate may arise from tetrathionate by chemical change. The facultative autotrophic ' $M$ ' strains isolated from concrete, attack thiosulphate in the same way as the ' $B$ ', ' $T$ ' and ' $K$ ' strains. The products of oxidation are identical, but the cultures vary in their rate of oxidation.

\section{Oxidation of tetrathionate}

Tetrathionate as a sole source of oxidizable sulphur is oxidized only by Thiobacillus $X$; the products of oxidation are sulphate and sulphuric acid according to equation (2). Oxidation of tetrathionate is incomplete because of the acid intolerance of the organism. In view of the intermediate formation of tetrathionate from thiosulphate by $T h$. thiooxidans, $T h$. concretivorus, the ' $M$ ', ' $B$ ', ' $T$ ' and ' $K$ ' strains as well as by $T$ hiobacillus $X$, it is of interest that only Thiobacillus $X$ can oxidize tetrathionate when it is supplied as the sole sulphur source.

\section{Oxidation of elementary sulphur}

Elementary sulphur is oxidized direct to sulphuric acid; this is brought about only by the four strictly autotrophic strains $T h$. thiooxidans, Th. concretivorus, Thiobacillus $X$ and $T h$. thioparus. The rate of acid formation and ultimate concentration of acid formed differs among the strains, and the latter is dependent on the acid tolerance of the strain. Th. thiooxidans and Th. concretivorus give the highest rates and the highest final concentration of acid, Thiobacillus $X$ shows a slower rate and lower final concentration, while the rate of sulphur oxidation by $T h$. thioparus and the final acid concentration is even less.

\section{Oxidation of $\mathrm{H}_{2} \mathrm{~S}$}

Oxidation of gaseous $\mathrm{H}_{2} \mathrm{~S}$ in air passed over appropriate liquid cultures is only brought about by $T h$. thiooxidans, $T h$. concretivorus and Thiobacillus $X$. The only product of oxidation of $\mathrm{H}_{2} \mathrm{~S}$ is sulphuric acid, although the accumulation of small amounts of elementary sulphur towards the end of incubation in acid media, and of thiosulphate in alkaline media, suggests that the formation of sulphur and thiosulphate by purely chemical means occurs first, this sulphur or thiosulphate then being oxidized to sulphuric acid by the organism. Oxidation of $\mathrm{H}_{2} \mathrm{~S}$ by $T h$. thiooxidans and $T$. concretivorus produces only enough acid to give a $\mathrm{pH}$ value of $2 \cdot 0$ under the given conditions, while oxidation of elementary sulphur and thiosulphate by the same organisms produces an acidity equivalent to a $\mathrm{pH}$ value of less than 1.0. As the same organisms are involved, difference in acid tolerance cannot be responsible. If elementary sulphur formed chemically from $\mathrm{H}_{2} \mathrm{~S}$ be an essential preliminary product in 
acid media, it is possible that this reaction does not proceed below $\mathbf{p H ~} \mathbf{2 \cdot 0}$, and the activity of the organisms ceases at this $\mathrm{pH}$ because no more sulphur becomes available. Some support for this hypothesis is derived from other investigations in these laboratories which indicate that $\mathrm{H}_{2} \mathrm{~S}$ dissolved in water is chemically oxidized by dissolved oxygen at very much slower rates under acid conditions than under alkaline conditions. It is, of course, also possible that the $\mathrm{pH}$ range of the enzyme systems involved in $\mathrm{H}_{2} \mathrm{~S}$ oxidation is different from those involved in the oxidation of elementary sulphur and thiosulphate. In contrast to the behaviour of $T h$. concretivorus and $T h$. thiooxidans in $\mathbf{H}_{2} \mathbf{S}$ the $\mathrm{pH}$ value of the medium decreases to 3.0 with Thiobacillus $X$; this value is the limit of its acid tolerance with elementary sulphur or thiosulphate as sulphur source.

\section{Identity of organisms isolated from concrete}

Th. concretivorus. This organism oxidizes thiosulphate, elementary sulphur and hydrogen sulphide according to the same reactions as $T h$.thiooxidans, and like $T h$. thiooxidans fails to utilize tetrathionate. It differs from $T h$. thiooxidans in being inhibited by higher concentrations of thiosulphate. The two organisms are closely related with regard to oxidation of sulphur compounds, but, as described earlier (Parker, 1945), they differ in their nitrogen requirements. $T h$. thiooxidans utilizes ammonia but is inhibited by nitrate, whereas $T h$. concretivorus utilizes ammonia or nitrate.

Thiobacillus $X$. This organism was previously considered to be closely related to $T h$. thioparus, but the present study reveals that the two organisms exhibit marked differences with regard to their oxidation of sulphur compounds. Th. thioparus oxidizes thiosulphate with formation of elementary sulphur and sulphate, whereas Thiobacillus $X$ converts thiosulphate first to sulphate and tetrathionate followed by a partial destruction of tetrathionate, forming sulphate and free sulphuric acid. Th. thioparus does not oxidize tetrathionate or $\mathrm{H}_{2} \mathrm{~S}$, whereas Thiobacillus $X$ readily oxidizes both compounds. The only point of similarity is their common power to oxidize elementary sulphur slowly to sulphuric acid. Thiobacillus $\boldsymbol{X}$ must therefore be considered a different species from $T h$. thioparus, and with regard to oxidation of sulphur compounds is much more closely related to $T h$. thiooxidans and $T h$. concretivorus. All three organisms utilize thiosulphate, elementary sulphur or $\mathrm{H}_{2} \mathrm{~S}$, and the route of oxidation of thiosulphate is by the same two reactions in each case. Thiobacillus $X$ differs from $T h$. thiooxidans and $T h$. concretivorus, however, in its acid tolerance. Oxidation of thiosulphate ceases with Thiobacillus $X$ at $\mathrm{pH} \mathrm{3 \cdot 0,} \mathrm{leaving} \mathrm{sulphate,} \mathrm{free} \mathrm{sulphuric} \mathrm{acid} \mathrm{and} \mathrm{some} \mathrm{unchanged} \mathrm{tetra-}$ thionate as the products of oxidation, while oxidation by $T h$. thiooxidans and $T h$. concretivorus only ceases at a $\mathrm{pH}$ value less than $1 \cdot 0$, the only products of oxidation being sulphate and free sulphuric acid. Thiobacillus $\boldsymbol{X}$ must therefore be considered as distinct from $T h$. thioparus on the one hand and $T h$. thiooxidans and $T h$. concretivorus on the other. Before classing Thiobacillus $X$ as a new species it is desirable to review the published literature on Th. thioparus. The strain of $T h$. thioparus examined in these studies was one isolated by Starkey in 1935, and Starkey (1935 a) considered it identical with the organism 


\section{Oxidation of sulphur compounds by sulphur bacteria}

isolated by Nathansohn (1902) and which was re-examined and named by Beijerinck (1904).

The original organism of Nathansohn was said to produce tetrathionate by oxidation of thiosulphate but Starkey was unable to detect tetrathionate as a product of thiosulphate oxidation by his strain, and suggested that the original Nathansohn strain was contaminated with an organism similar to the ' $B$ ', ' $T$ ' and ' $K$ ' strains. Production of acid was not specifically mentioned by Nathansohn or Beijerinck, but slight acid formation by the original culture cannot be excluded.

Nathansohn's original strain was said to produce sulphur from thiosulphate, and Starkey's strain produces sulphur and sulphate in the ratio of 4:6. Thiobacillus $X$ produces a thin pellicle of sulphur, but very much less than that produced by Starkey's organism. It is possible that the sulphur formed by Nathansohn's original organism and by Thiobacillus $X$ is due to chemical reaction between thiosulphate and tetrathionate, whereas the sulphur formed by Starkey's strain is directly produced from thiosulphate.

According to Beijerinck (1904), Th. thioparus can oxidize thiosulphate, tetrathionate, sulphur, sulphides and $\mathrm{H}_{2} \mathrm{~S}$. In view of the production of tetrathionate from thiosulphate by Thiobacillus $X$ and its ability to oxidize thiosulphate, tetrathionate, sulphur and $\mathrm{H}_{2} \mathrm{~S}$, it seems more likely that the original strain of Nathansohn was not impure; that its oxidizing powers as described by that author were correct; and that the strain Thiobacillus $X$ isolated from concrete is identical with or very similar to the original $\mathrm{Th}$. thioparus. Starkey's strain, which he considered identical with the original $T h$. thioparus, would appear to differ from both $T h$. thioparus as isolated by Nathansohn and Thiobacillus $X$.

Since the completion of the present work, Vishniac (1952) published a manometric study of the oxidation of thiosulphate by a strain considered identical with Starkey's strain of $T h$. thioparus. It was found that this organism gave qualitative tests for tetrathionate, and that its oxygen uptakes were consistent with tetrathionate formation. Vishniac considered that oxidation of thiosulphate by the strain used proceeded through tetrathionate, trithionate and dithionate to sulphate. It appears likely that Vishniac's strain was very similar to Thiobacillus $X$ and to $T h$. thioparus as originally described by Nathansohn; although Vishniac stated that a culture of Starkey's strain of Th. thioparus appeared identical with his own, if examined closely it seems probable that they would differ in the same way as Thiobacillus $X$ and $T h$. thioparus differed in the present work.

' $M$ ' strains. Those cultured from concrete appear to be closely related to the ' $\mathrm{T}$ ' and ' $\mathrm{K}$ ' strains of Trautwein and Thiobacillus $B$ with regard to oxidation of sulphur compounds. All strains oxidize thiosulphate with the formation of tetrathionate, and with an increase in $\mathrm{pH}$ value they are similar in their action on the other forms of sulphur examined.

The authors wish to thank Mr J. A. McIntosh, Acting Chief Engineer of Sewerage, Melbourne, and Metropolitan Board of Works, for permission to publish this paper, and Miss E. M. Jackson who assisted with the preparation of media. 


\section{REFERENCES}

BeiJerinck, M. W. (1904). Über die Bakterien welche sich im Dunklen mit Kohlensäure als Kohlenstoffquelle ernähren können. Zbl. Bakt. (2 Abt.), 11, 593.

Bergey's Manual of Determinative Bacteriology (1948). 6th ed. Edited by BrEed, R. S., Murray, E. G. D. \& Hitchens, A. P. Baltimore. The Williams \& Wilkins Co.

Debus, H. (1888). Chemical investigation of Wackenroder's solution, and explanation of the formation of its constituents. J. chem. Soc. 53, 278.

JACoBsen, H. C. (1914). Die Oxydation von Schwefelwasserstoff durch Bakterien. Folia microbiol., Delft, 3, 155.

Le Page, G. A. \& Umbreit, W. W. (1943). Phosphorylated carbohydrate esters in autotrophic bacteria. $J$. biol. Chem. 147, 263.

Lipman, J. G., Waksman, S. A. \& Joffe, J. S. (1921). The oxidation of sulphur by soil micro-organisms. Soil Sci. 12, 475.

Nathansohn, A. (1902). Über eine neue Gruppe von Schwefelbakterien und ihren Stoffwechsel. Mitt. zool. Sta. Neapel, 15, 665.

Niel, C. B. van (1931). On the morphology and physiology of the purple and green sulphur bacteria. Arch. Mikrobiol. 3, 1.

Parker, C. D. (1945). The corrosion of concrete. I. The isolation of a species of bacterium associated with the corrosion of concrete exposed to atmospheres containing hydrogen sulphide. Aust. J. exp. Biol. med. Sci. 23, 81.

Parker, C. D. (1947). Species of sulphur bacteria associated with the corrosion of concrete. Nature, Lond. 159, 439.

Pomeroy, R. (1936). The determination of sulphides in sewage. Serwage Wks. J. 8, 572.

Starkey, R. L. (1925). Concerning the physiology of Thiobacillus thiooxidans an autotrophic bacterium oxidizing sulphur under acid conditions. J. Bact. $10,135$.

Starkey, R. L. $(\mathbf{1 9 3 4} a)$. Cultivation of organisms concerned in the oxidation of thiosulphate. J. Bact. 28, 365.

Starkey, R. L. (1934b). The production of polythionates from thiosulphate by microorganisms. J. Bact. 28, 387.

Starkey, R. L. (1935a). Products of the oxidation of thiosulphate by bacteria in mineral media. J. gen. Physiol. 18, 325.

Starkey, R. L. (1935b). Isolation of some bacteria which oxidize thiosulphate. Soil Sci. 39, 197.

Trautwern, K. (1921). Beitrag zur Physiologie und Morphologie der Thionsäurebakterien (Omelianski). Z Zbl. Bakt. (2 Abt.), 53, 513.

Vishniac, W. (1952). The metabolism of Thiobacillus thioparus. I. The oxidation of thiosulphate. J. Bact. 64, 363.

Vogler, K. H. (1942). Studies on the metabolism of the autotrophic bacteria. II. The nature of the chemosynthetic mechanism. J. gen. Physiol. 26, 103.

Vogler, K. G. \& Umbreit, W. W. (1942). Studies on the metabolism of the autotrophic bacteria. III. The nature of the energy storage material active in the chemosynthetic process. J. gen. Physiol. 26, 157.

Waksman, S. A. $(1922 a)$. Micro-organisms concerned in the oxidation of sulphur in the soil. $J$. Bact. $7,231$.

Waksman, S. A. (1922b). Micro-organisms concerned in the oxidation of sulphur in the soil. III. Media used for the isolation of sulphur bacteria from the soil. Soil Sci. 13, 329.

Waksman, S. A. \& Starkey, R. L. (1923). On the growth and respiration of sulphur oxidizing bacteria. J. gen. Physiol. 5, 285.

(Received 8 August 1952) 